\title{
A plea for simplicity in the classification of ankle fractures
}

\author{
R. S. Phillips \\ F.R.C.S.E. \\ Consultant Orthopaedic Surgeon, North Manchester Group of Hospitals, \\ Department of Orthopaedics, Crumpsall Hospital, Manchester 8 \\ C. J. E. Monk \\ M.Ch.(Orth.), F.R.C.S. \\ Senior Registrar, Department of Orthopaedics, \\ Royal Southern Hospital, Liverpool 8 \\ G. A. BAlmer \\ F.R.C.S.E. \\ Senior Registrar, University Department of \\ Orthopaedics, Manchester Royal Infirmary, \\ Oxford Road, Manchester 13
}

\section{Summary}

1. Ashurst and Bromer's classification of ankle fractures is a useful one, but falls into the complexities of subdivision into sequential progression of severity, i.e. 'degrees' of fracture.

2. A similar criticism can be made of the Lauge-Hansen classification which has an added semantic disadvantage. Doubts are also cast upon the validity of the direct application of experimental results in cadaveric specimens to a clinical series.

3. A third classification, essentially a modified form of those preceding it but with both an anatomical and a functional basis is presented, in the belief that it can provide evidence of: (a) the mechanism of production and hence the achievement of reduction; and (b) the recognition of significant ligamentous damage, i.e. the recognition of major from minor, stable from unstable injuries-when used in association with radiographs taken while straining the ankle under anaesthesia.

4. An Appendix to the paper (pp. 210-211), giving a more detailed account of our revised classification, is included.

\section{Introduction}

The classification of a group of fractures can be scrupulous in its anatomical detail, but unless it has practical significance it degenerates into a pedantic exercise. When a group of diseases or injuries displays certain common features, to seek out the differences that exist in aetiology, clinical presentation and pathology is useful in formulating sensible plans of management. Rose (1962) pointed out that systematic classification is a logical process of collecting under a common name a number of objects which are alike in one or more respects. But the importance of such associations lies less in the features common to the group, but more in the persistent, but usually less obvious, differences that exist.

\section{Requirements of classifications}

Ankle fractures constitute a complex group of injuries. Any fracture involving a joint may be complicated by secondary osteoarthritis. Treatment must be aimed at the restoration of normal function by reconstituting congruity of articular surfaces. Most fractures are diagnosed clinically, but the characteristics of the fracture are seen on radiographs. Recognition of broken bones can be easy, but the associated ligamentous damage that may exist is recognized with difficulty-or not at all, unless one presupposes a knowledge of the mechanism of the injury, i.e. recognition of the force producing it. Hence, a rational classification of fractures and fracture dislocations at the ankle should be based on the predominant force acting on the ankle at the moment of injury, for only in this way can the route of displacement be retraced to achieve reduction.

Ankle fractures are common and a busy casualty department will deal with a large number in a short period of time. The bulk of these are dealt with by junior staff who, at an early stage in their professional career, must use their judgment in recognizing fracture types. In so doing they assume the responsibility of deciding which injury is of minor and which is of major significance (and associated with important morbidity) of differentiating the stable from the unstable injury and of electing to follow a course of treat- 
ment which, by its planned orderliness, results in the functional restoration of the part. This implies that they have an understanding of biomechanics and a wealth of clinical experience or, alternatively, that they can pick out certain salient features on a radiograph which will fit into an easily recognizable and understandable pattern.

A classification of ankle fractures should be simple and immediately applicable to any individual problem. It should be based on information obtained from the patient's history and clinical and radiological examinations, i.e. founded on observed clinical data. In the limited dissections of open operations some corroborative evidence justifying the classification may be found. Mechanical experiments in cadaveric limbs can provide a wealth of information on the pathogenesis of such fractures. This ideal classification should be a clinical one. However, it is well known that 'the history of injury is often disappointing' (Rose, 1962). The confusion of the accident and the disquieting effect of pain make it unlikely that the patient will have a clear recollection of the position of his foot or the direction of the causative force at the time of injury. Certainly physical examination may reveal specific areas of bruising or tenderness overlying fractured bony processes or damaged ligaments. Deformity of foot and ankle may be a helpful clue, but in fact has little bearing on the full extent of displacement at the time of injury. Radiographs provide considerable information if they are of good quality and taken in at least two different planes. Oblique views and, particularly, views while straining the ankle under anaesthesia are a valuable aid.

The experimental production of fractures in cadaveric limbs is essential for confirmation, but the facts obtained must be interpreted with caution and applied judiciously to a clinical classification. The wearing of footwear, the protective contraction of muscle at the time of injury and the influence of transmission of body weight are features which cannot be fully considered in laboratory experiments, yet are acting significantly at the moment of fracture in clinical practice.

Importantly, any classification which is based on the recognition of forces producing a fracture stands or falls (other things being equal) upon the functional and anatomical results of logically applied treatment.

\section{Historical aspects}

Astley Cooper (1822) used a simple classification based on observation. Patterns of frac- ture were recognized according to the displacement of the proximal fragment, i.e. the distal tibia. While failing to take into account the complexities of the fracture and associated ligamentous rupture, it did provide the clue to reduction.

The trend in experimental production of ankle fractures in cadaveric limbs was set by Maisonneuve (1840), Bonnet (1845), Tillaux (1872) and Rochet (1890). These men described specific fracture types or associated ligamentous damage by applying controlled forces in certain planes. Of necessity, in the absence of radiographs, such experiments were valuable, but interpretations were somewhat speculative when applied to clinical series. Honigschmied (1877) listed his results of cadaveric studies, but in so doing produced a somewhat academic classification.

Destot (1911), Quenu (1912a, b) and Quenu \& Mathieu (1912) returned to a more obviously clinical basis for their interpretation of ankle fractures. Tanton (1916), combining the views of these latter two, recognized: (a) fractures of the malleoli-isolated or associated, and (b) fractures of the tibial pestle (lower end of the tibial shaft)-isolated, associated or complete. This, at least, was a division according to observed radiographic and anatomical fact, but it paid no heed to the mechanism of production.

Two authors whose work is essential for an understanding of fractures of the ankle are Ashurst and Lauge-Hansen. The former (Ashurst \& Bromer, 1922) undertook a critical analysis of 300 fractures, so formulating a comprehensive classification based on the principal deforming force producing the fracture complex. Reliance was placed on the experimental evidence of previous authors, but only in a confirmatory way. If one excludes those fractures grouped as due to direct violence, then ankle injuries are caused by external rotation, abduction, adduction and vertical compression. Each group was subdivided into first, second and third degrees, depending on certain recognizable clinical and radiographic features. This numerical index of severity implied a sequential prolongation of the deforming force in either time-duration or magnitude or both, which, on the evidence, did not seem justified.

Lauge-Hansen (1948, 1950, 1952, 1953) produced, experimentally, a sequential group of fractures and fracture dislocations determined not only by the deforming force applied, but also by the position in which the foot was placed at the time during which the deforming force was acting. This 'genetic' classification, he claimed, allowed 'genetic' reduction. Realizing the shortcomings of such experimental results, he related 
them to a group of clinical injuries and found complete accord.

One drawback to the understanding of LaugeHansen's work is his use of words which can be misunderstood and, therefore, are ill-used. He used the terms 'pronation' and 'supination' in reference to movements of the foot when, in fact, these are specifically defined in standard works of anatomy (Cunningham, 1964) as rotatory movements of the radius and ulna at the superior and inferior radioulnar joints-a state of affairs not comparable to that existing in leg and foot. This may seem pedantic, but to explain these terms to students and surgeons in training in reference to the foot makes confusion more confused.

The position of the foot and ankle at the time of experimentally produced fracture is easily determined, but this cannot be directly applied to a clinical series where the factors of footwear, muscle contraction and transmission of body weight are playing a part.

Despite these criticisms the classifications of Lauge-Hansen and Ashurst are well founded and have meaning in clinical orthopaedics. Both take into account the mechanism of injury, both differentiate minor fractures from those of greater functional significance and both consider the detection of ligamentous rupture (i.e. possible ankle instability). However, can they be simplified for the understanding of those who must use them?

\section{Object of present study}

This present study was undertaken to determine the possibility of readily recognizing from these classifications, suitably modified, that: (a) certain patterns of fracture are produced by specific deforming forces; (b) certain fractures are associated with significant ligamentous injuries, and (c) that features of the X-ray provide the clue to ankle instability.

\section{Method}

In order to analyse critically the merits of methods of classification of ankle fractures, a large series of such fractures has been studied clinically and radiologically. This series has been classified in three ways. The ease with which any one method can be applied to this fracture series will be shown, but, more importantly, the signi-

TABLE 1

Lauge-Hansen classification

\begin{tabular}{|c|c|}
\hline Classification & $\begin{array}{l}\text { No. of } \\
\text { fractures }\end{array}$ \\
\hline $\begin{array}{l}\text { A. Supination-eversion } \\
\text { Stage 1: Tear of anterior inferior tibio-fibular ligament } \\
\text { Stage 2: Oblique spiral fracture distal fibula } \\
\text { Stage 3: As above + posterior margin of tibia } \\
\text { Stage 4: As above + fracture of medial malleolus at its base - or detach- } \\
\text { ment of deltoid ligament } \\
\text { (variant-oblique spiral fracture of distal tibia) }\end{array}$ & $\begin{array}{r}60 \\
16 \\
30 \\
1\end{array}$ \\
\hline $\begin{array}{l}\text { B. Supination-adduction } \\
\text { Stage 1: Transverse fracture of lateral malleolus (or avulsion of lateral } \\
\text { ligament of ankle) } \\
\text { Stage 2: As above + vertical fracture of medial malleolus }\end{array}$ & $\begin{array}{l}44 \\
11\end{array}$ \\
\hline $\begin{array}{l}\text { C. Pronation-abduction } \\
\text { Stage 1: Horizontal fracture near the base of the medial malleolus } \\
\text { (Stage 2: Avulsion of anterior and posterior inferior tibio-fibular ligaments } \\
\text { often with a bony shell) } \\
\text { Stage 3: An oblique or transverse fracture of fibula } 0.5-1 \mathrm{~cm} \text { above the }\end{array}$ & 23 \\
\hline $\begin{array}{l}\text { distal articular surface of tibia } \\
\text { D. Pronation-eversion }\end{array}$ & \\
\hline $\begin{array}{l}\text { D. Pronation-eversion } \\
\text { (Stage 1: As for Stage } 1 \text { pronation-abduction) } \\
\text { Stage 2: Disruption of interosseous ligament complex } \\
\text { Stage 3: A spiral fracture of fibula more than } 8-9 \mathrm{~cm} \text { above the tip of } \\
\text { the malleolus } \\
\text { Stage 4: Detachment of posterior margin of tibia }\end{array}$ & 5 \\
\hline E. Pronation-dorsiflexion & 7 \\
\hline F. Direct violence & 2 \\
\hline G. Maisonneuve & 1 \\
\hline Total & 209 \\
\hline
\end{tabular}


TABLE 2

Ashurst and Bromer classification

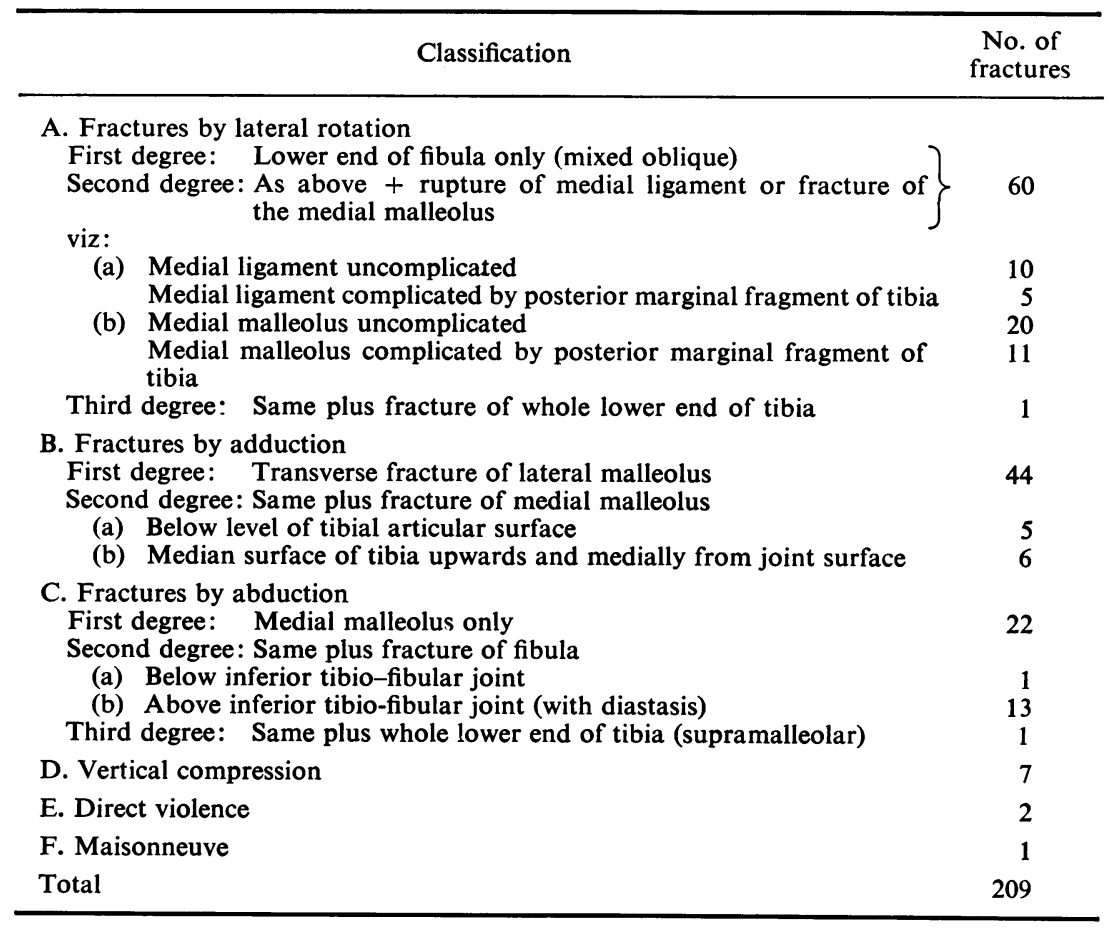

ficant exceptions to each will be stressed and illustrated.

Lauge-Hansen's classification has been claimed by many as the answer to the understanding of ankle fractures. His classification is reproduced in Table 1. Our series of 209 ankle fractures has been analysed accordingly. The classification of Ashurst \& Bromer (1922) is reproduced in Table 2 and again our series has been analysed in accordance with this.

One of us (Monk, 1966) has repeated LaugeHansen's work on the experimental production of ankle fractures. It was not found possible to endorse completely all Lauge-Hansen's conclusions. This was particularly true of the 'supination-eversion' (lateral rotation)* injury, where it was found that the sequence of events he described could not be reproduced. Lauge-Hansen further stated that if the foot is held in 'pronation' while a lateral rotation force is applied (after preliminary fracture of the medial malleolus) a fracture occurred in the lower third of

\footnotetext{
* The term 'eversion' as used by Lauge-Hansen is interpreted as meaning 'lateral rotation'.
}

the fibula above the inferior tibio-fibular joint. Attempts to reproduce this were unsuccessful. The clinical examples of fibular fractures at this level were found to have associated complete separation of the inferior tibio-fibular joint. Further experimental studies may be justified, but it may be more convenient, and indeed more accurate, to regard the pronation-eversion (lateral rotation) injury simply as a variant of the pronation-abduction group.

As a result of experimental work one of us (Monk, 1966) has formulated a classification which is in two parts; the first is a division into the number of bones fractured and the second an assessment of the mechanism involved, but carrying with it the implication of ligamentous damage not visible radiographically. This classification is reproduced in Table 3 and again our series of 209 fractures analysed accordingly.

In all three methods of classification fractures due to vertical compression (the pronation-dorsiflexion group of Lauge-Hansen) are readily recognized and are excluded from further discussion-Fig. 1. This is also true of two fractures produced by direct violence. The rare fracture 
TABLE 3

Proposed simplified classification (Monk, 1966)

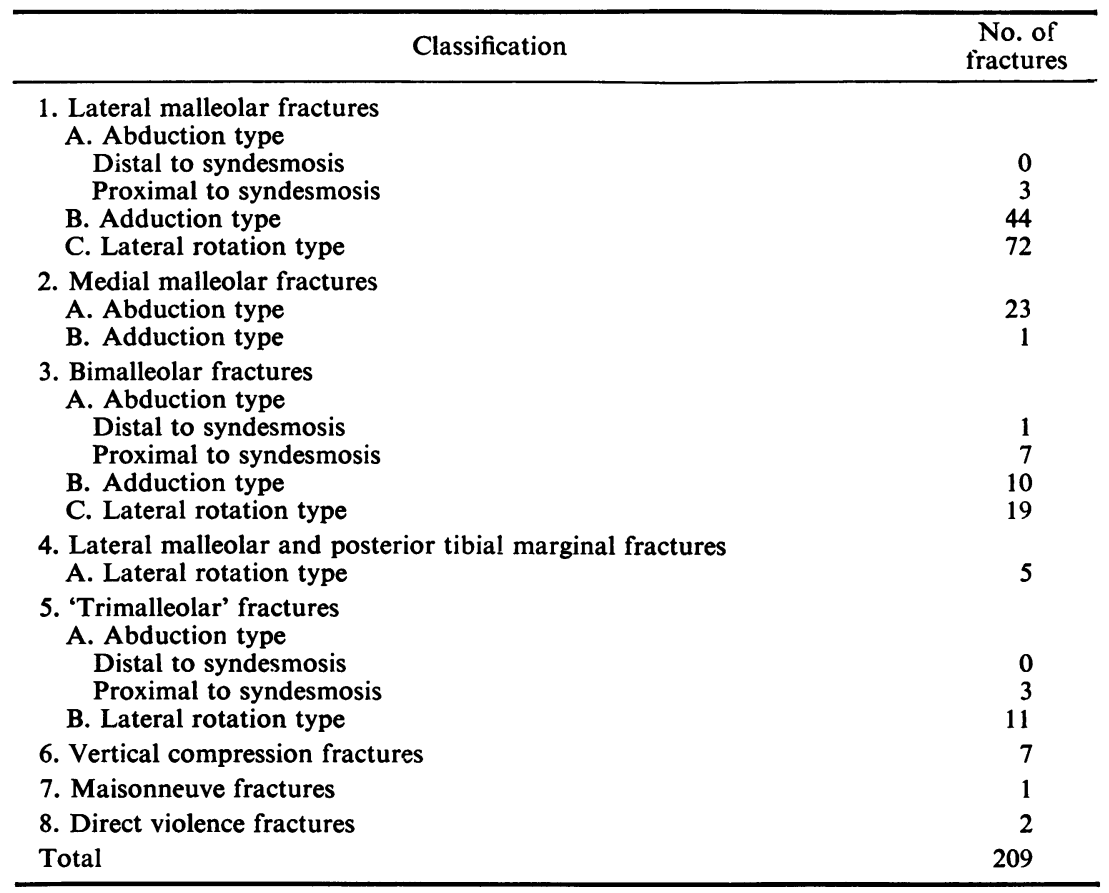

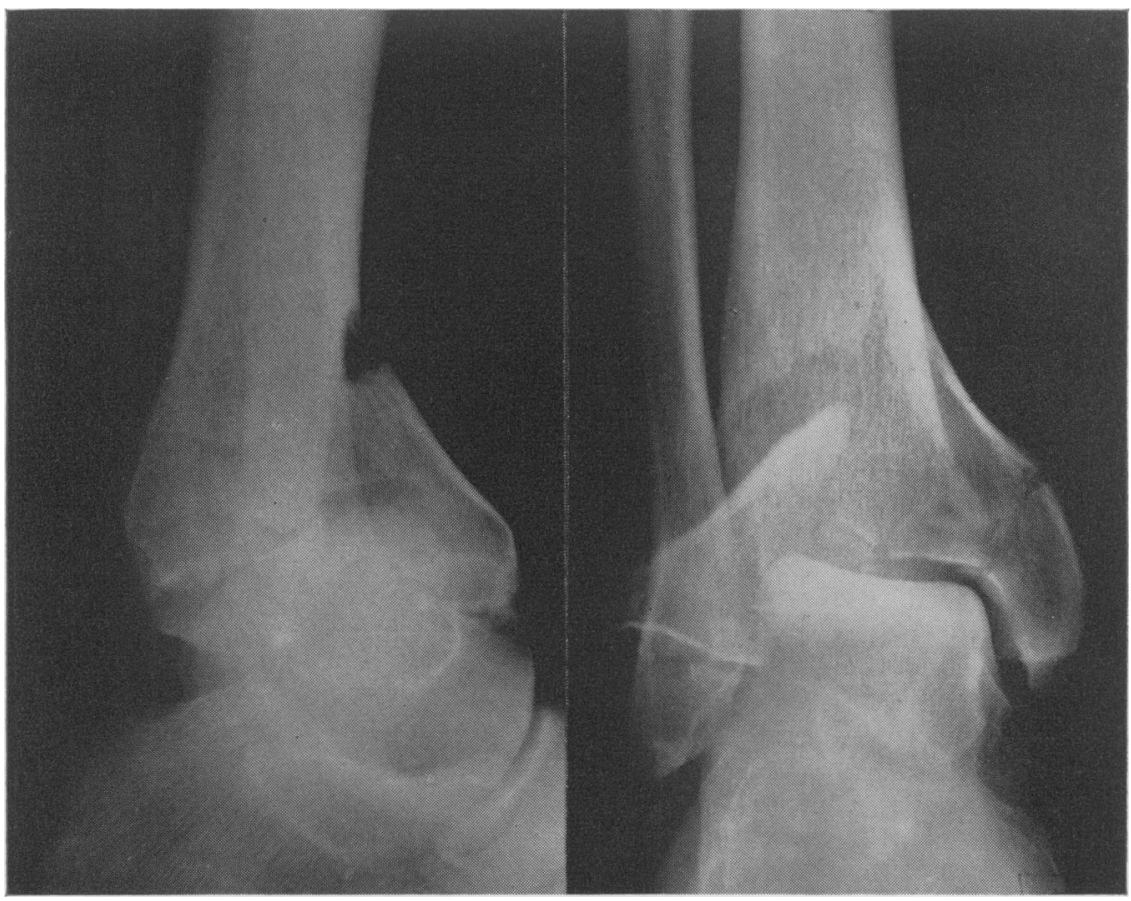

Fig. 1. This vertical compression fracture is characterized by the large triangular fragment from the anterior aspect of the distal tibia. A common feature also visible here is comminution of the tibial articular surface. 
described by Maisonneuve (1840), although produced by lateral rotation, has been segregated (Fig. 2).

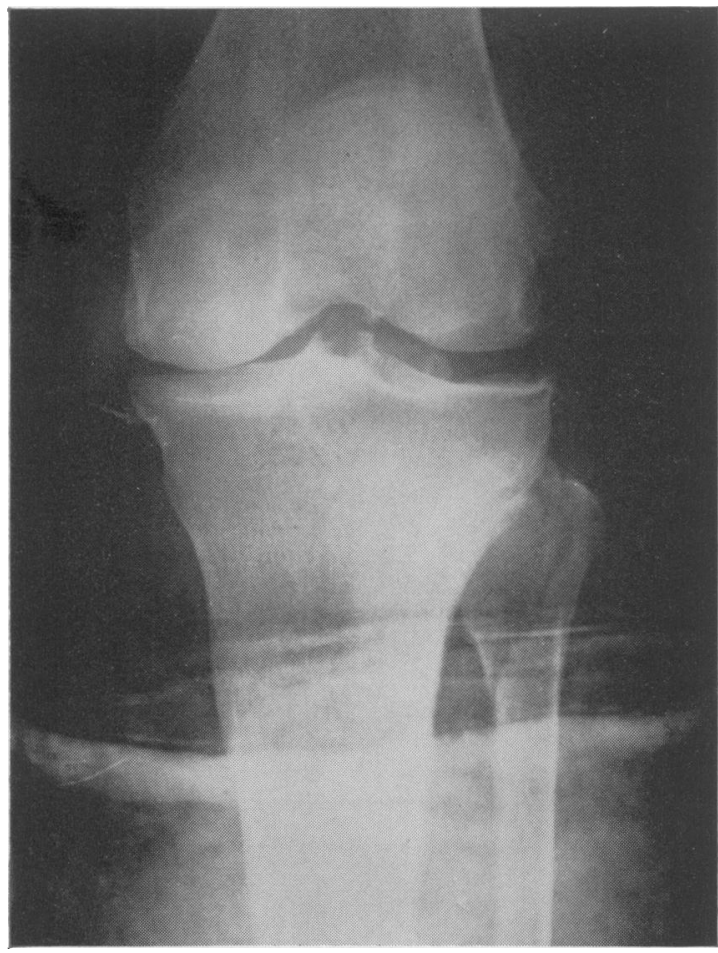

Fig. 2. In this Maisonneuve fracture the fibula is fractured at its neck. The lateral rotation strain produces typically an oblique fracture line directed upwards and laterally.

\section{Lateral rotation}

In the group of injuries produced by lateral rotation the characteristic feature is the oblique or spiral fracture of the fibula (Fig. 3). Both Lauge-Hansen and Ashurst recognized this as the first stage of this fracture complex (although preceded by rupture of the anterior inferior tibiofibular ligament). In the third classification (Monk, 1966) an additional twelve fractures are included in the group of lateral malleolar fractures caused by lateral rotation. These twelve are unstable injuries because of the co-existence of a ruptured medial ligament (Fig. 4)-a feature of importance which, in less obvious examples, can be missed by the inexperienced. The implication is that unimalleolar fractures are not, of necessity, basically stable. Both Lauge-Hansen and Ashurst consider associated rupture of the medial ligament as a continuation of the lateral rotation force, making provision for this, includ- ing it together with that group in which there is a fracture at the base of the medial malleolus. Rightly, this latter falls into our bi-malleolar lateral-rotation series.

When there is an associated posterior marginal fragment of the tibia (so-called 'third malleolus') there is little discrepancy between Lauge-Hansen and Ashurst, other than to state that there is a reversal in sequence of production, i.e. LaugeHansen believes that the posterior marginal fragment is produced before the medial malleolus fractures or the medial ligament ruptures. That this is not always so is shown in Fig. 5. But in our classification one can avoid the rather irrelevant argument of sequential production of this fracture-ligament complex by regarding it as a separate entity. An associated rupture of the medial ligament, determined by taking strained views, causes this lesion to assume the functional significance of a 'tri-malleolar' fracture. Only one fracture could be grouped in the Ashurst third-degree external rotation type, i.e. where fracture of the distal tibia represents the medial malleolus and posterior marginal fragment. Likewise, it is easily recognized in the Lauge-Hansen method and falls into our bimalleolar lateral rotation group.

\section{Adduction}

Between Ashurst's adduction group and LaugeHansen's supination-adduction group there is no difference of note. In our classification the only difference is that one fracture was placed among the medial malleolus group, implying an intact lateral malleolus, but with rupture of the lateral ligament of the ankle-a point of functional importance to be discussed in a later communication. Fig. 6 illustrates a typical adduction fracture.

\section{Abduction}

Fractures produced by abduction provoke the most serious disagreement among the classifications. Although Lauge-Hansen recognizes that the first stage of pronation-abduction and pronation-eversion (lateral rotation) is a horizontal fracture near the base of the medial malleolus (Fig. 7), he reckons that each force, continuing to act, produces its own specific fracture-ligament rupture complex. It has already been stated that this has not been confirmed experimentally. If, in fact, Lauge-Hansen's pronation-abduction and pronation-eversion (lateral rotation) series are grouped together, then they differ little from Ashurst's abduction group, although the latter does emphasize that in abduction injuries the fracture of the fibula may be distal to the inferior tibio-fibular joint, or proximal to it with 


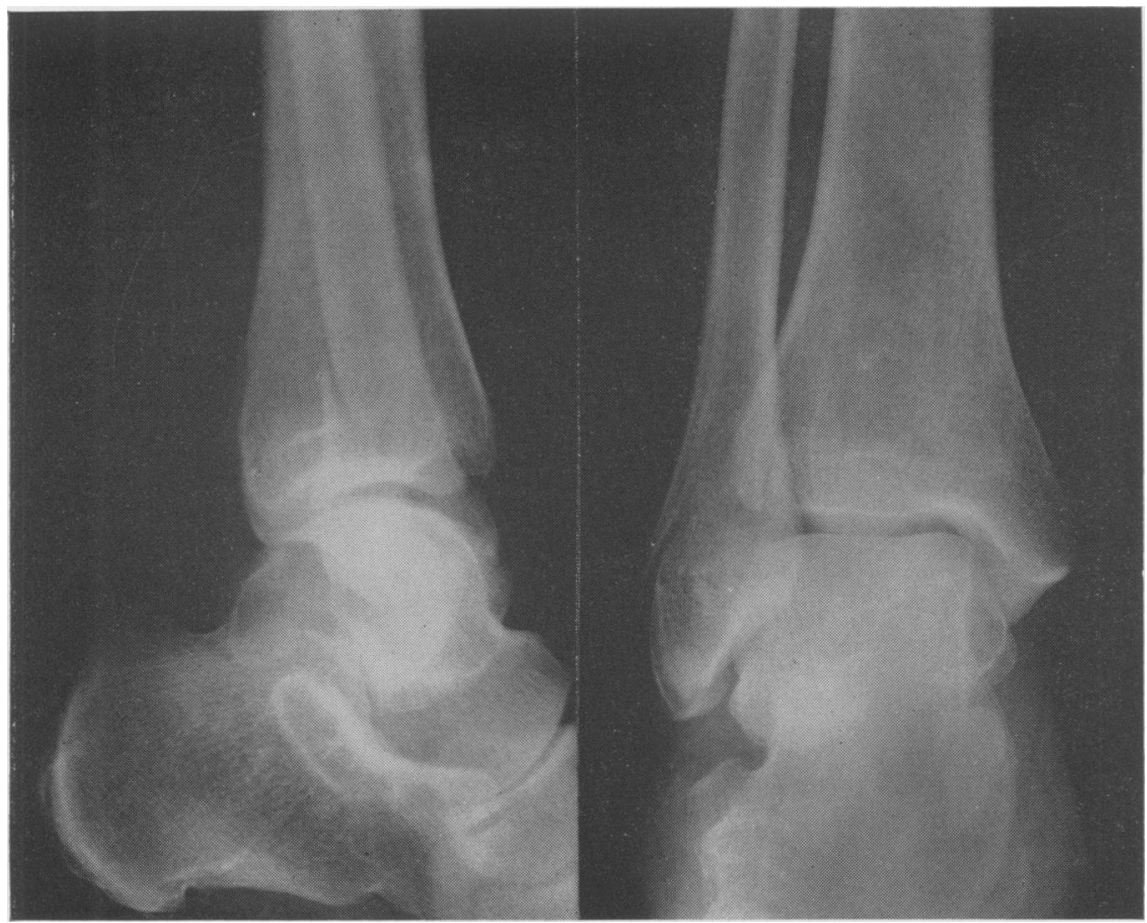

FIG. 3. A lateral rotation fracture in which the characteristic feature is a fracture line in the distal fibula, either oblique or spiral, directed upwards and backwards but commencing at the level of the distal tibial articular surface. This is seen most clearly on the lateral view.

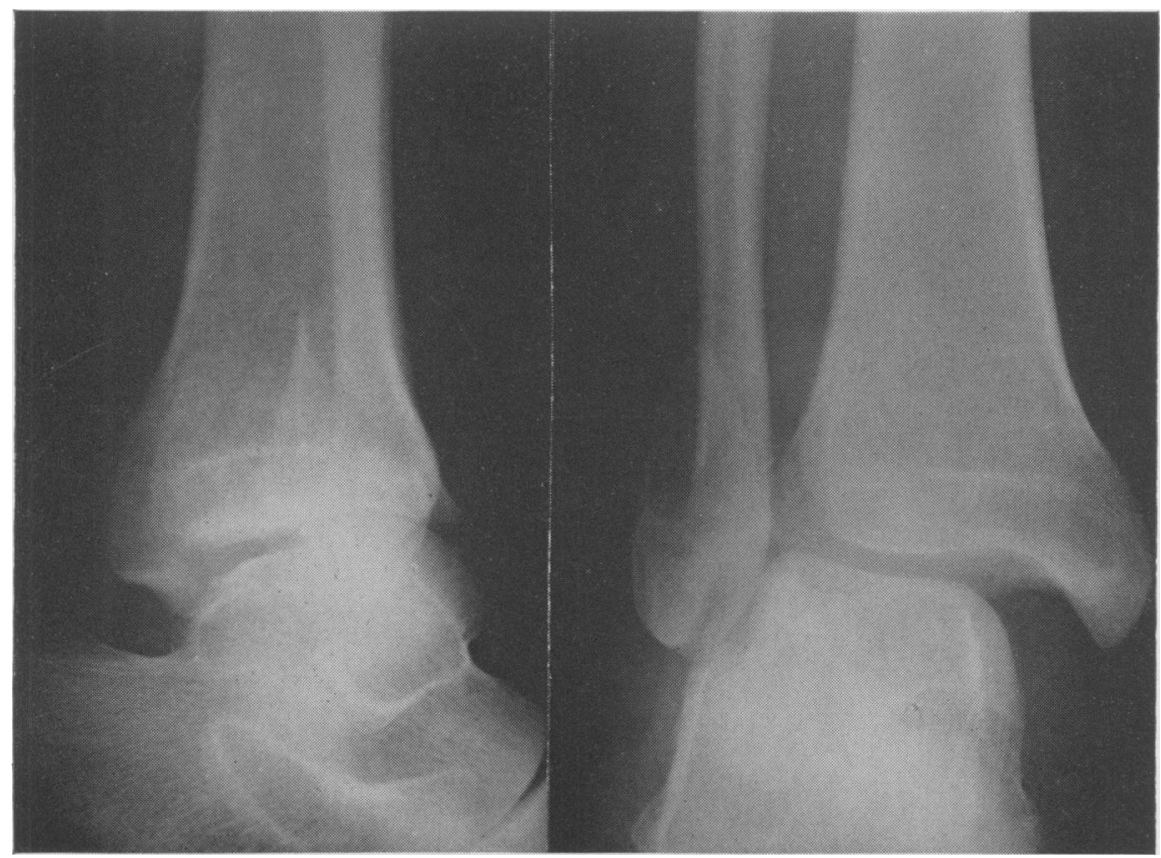

Fig. 4. In this lateral rotation injury the typical oblique fracture of the fibula is noted and is displaced. On the antero-posterior view the talus (with the lateral malleolus) is displaced laterally but the proximal fibular fragment maintains a normal relationship to the tibia, i.e. there is not complete disruption of the inferior tibio-fibular syndesmosis. With an intact medial malleolus such displacement is occurring because of complete rupture of the medial (deltoid) ligament. 


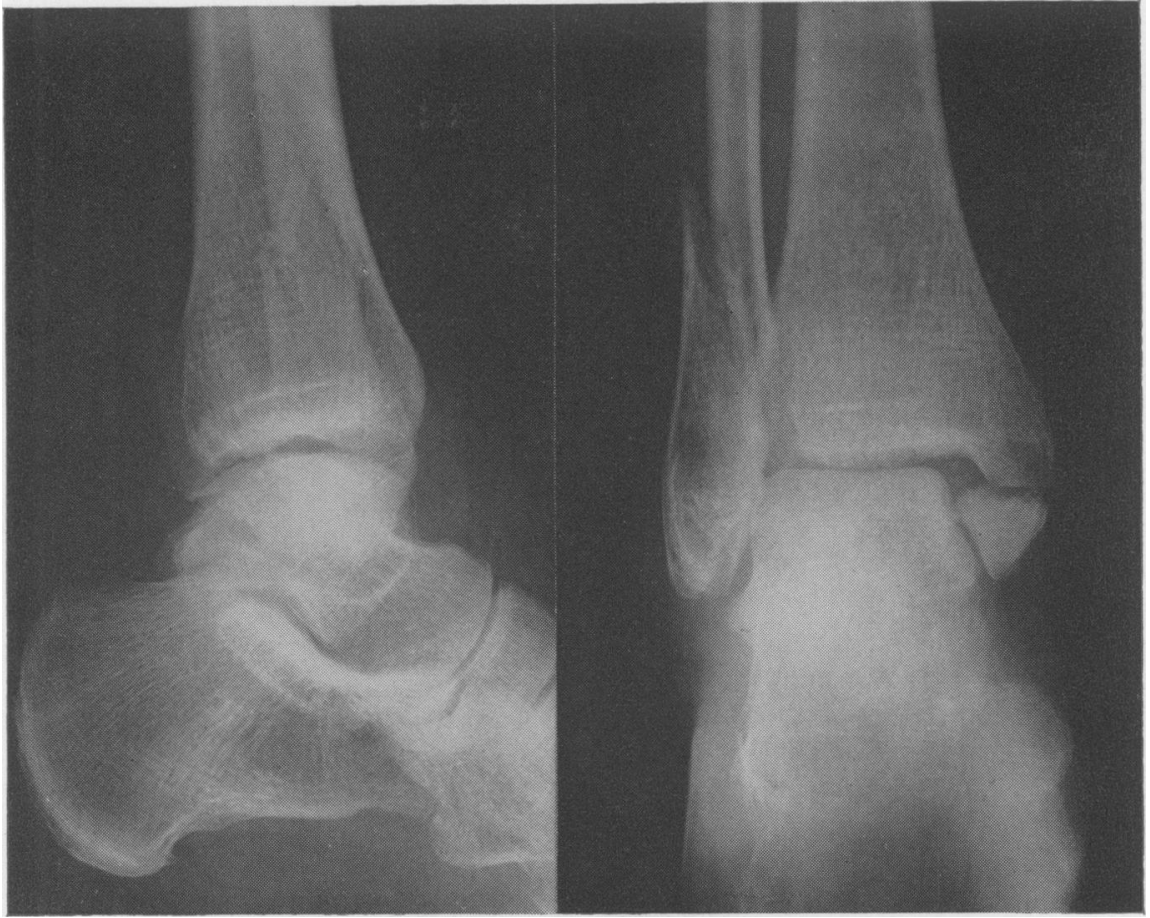

FIG. 5. In this lateral rotation injury the typical oblique fracture of the fibula is noted. The fracture of the medial malleolus is transverse in the antero-posterior plane and is just distal to the joint level. Note that the posterior tibial margin is intact.

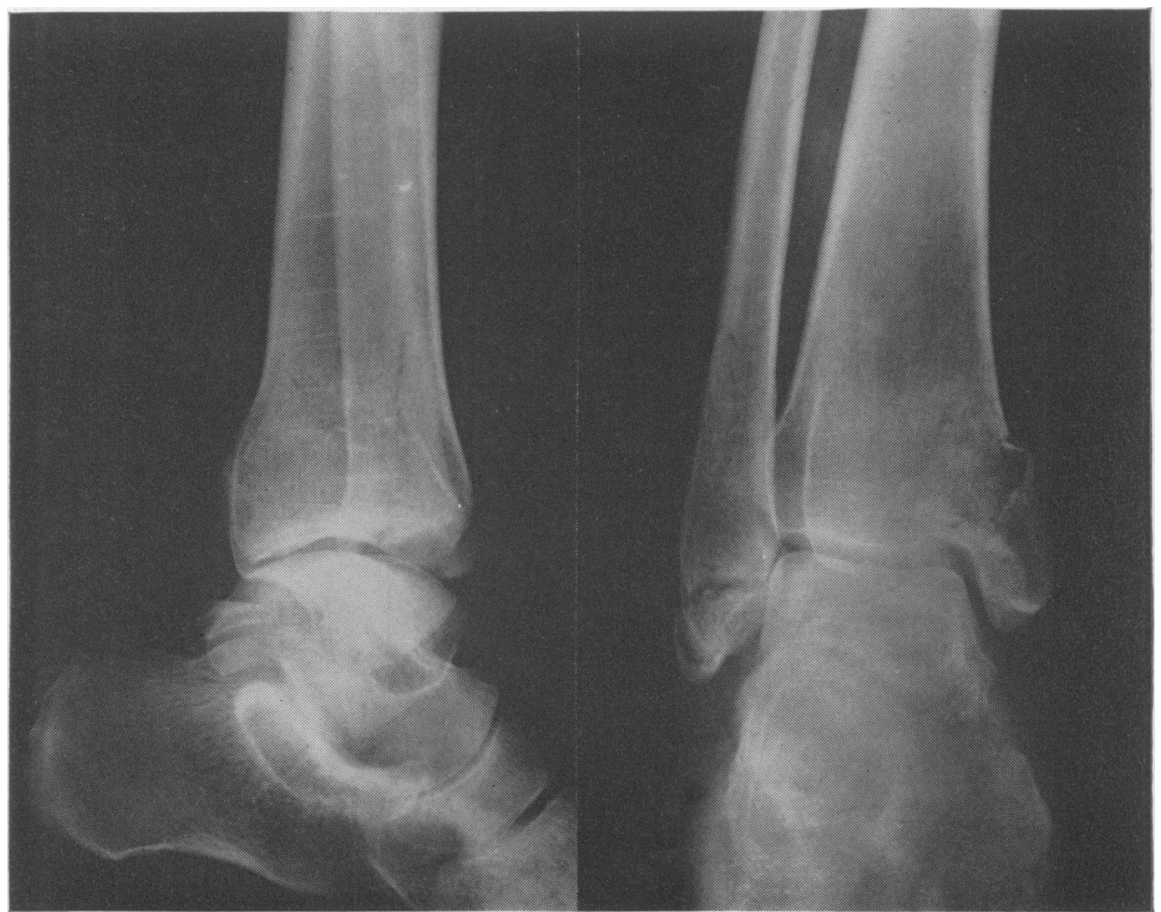

FIG. 6. In this typical adduction fracture of the ankle the fibular malleolus is fractured distal to the joint level and almost transversely, The fracture of the medial malleolus is almost vertical and involves the 'tibial' as opposed to the medial malleolar articular surface. 


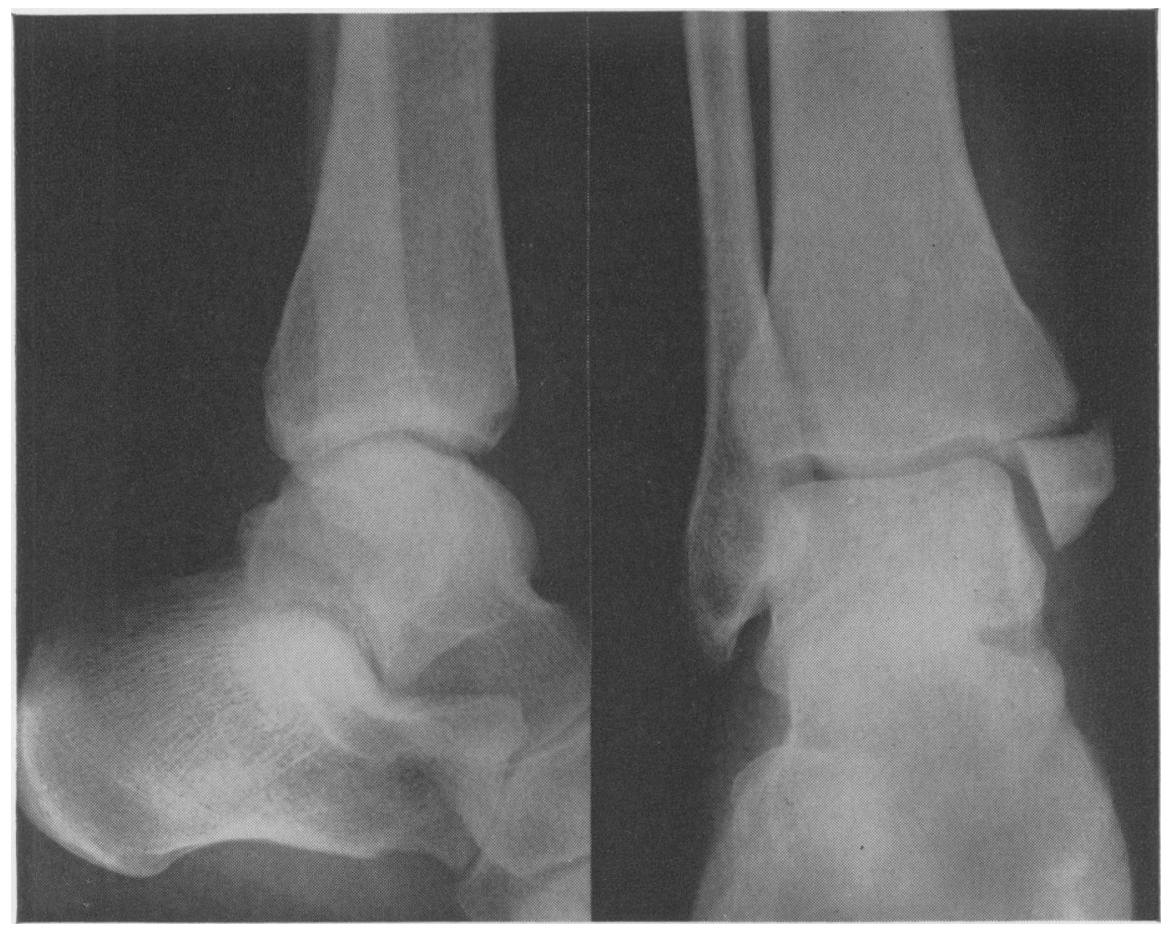

Fig. 7. In this abduction fracture the fibular malleolus is intact. The medial malleolus is fractured just proximal to the joint level. The fracture line is nearly horizontal.

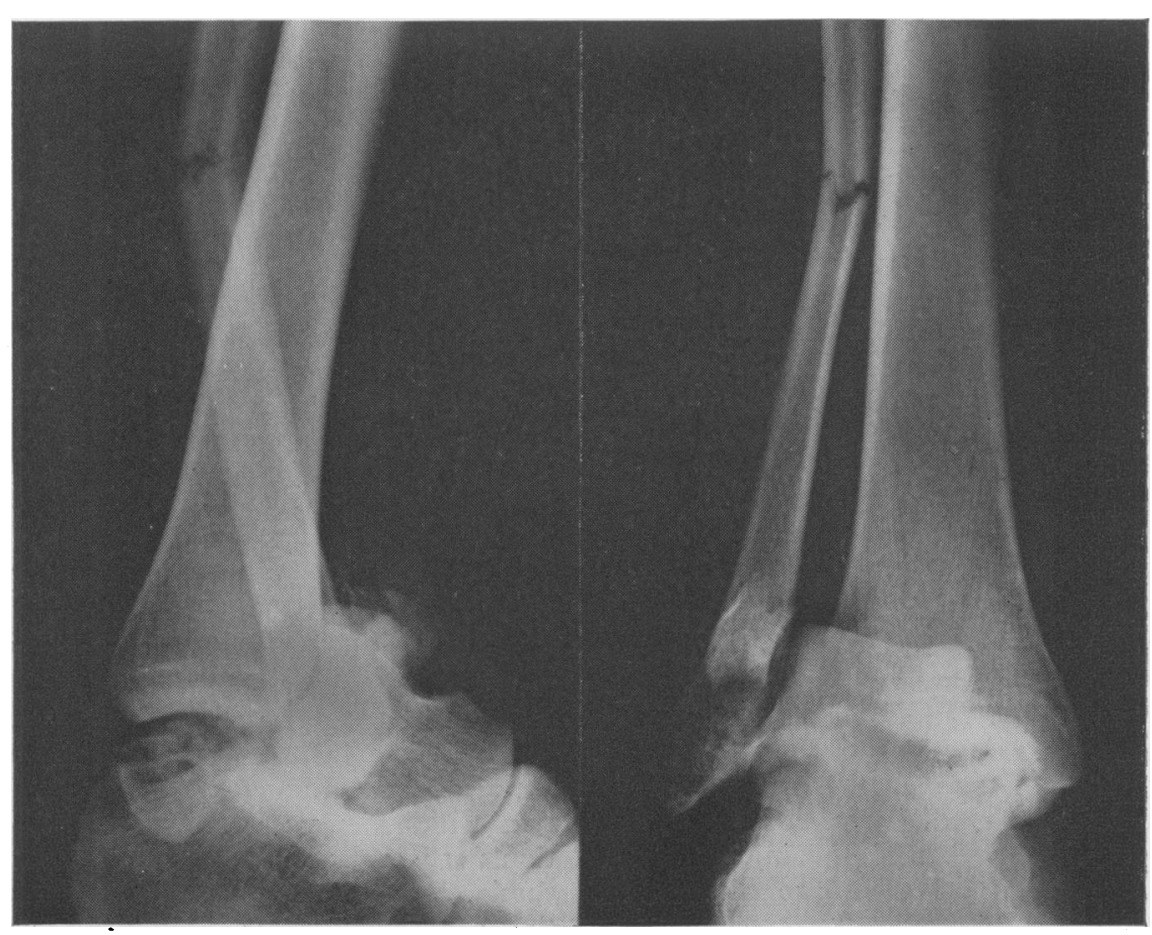

Fig. 8. This is a typical abduction fracture in which the fibular shaft is fractured transversely. The talus and the distal half of the fibula are displaced laterally so that the normal relationship of fibula to tibia is lost. This signifies complete disruption of the inferior tibio-fibular syndesmosis (classical diastasis). The nearly horizontal fracture of the medial malleolus is also seen. The posterior tibial margin is intact. 


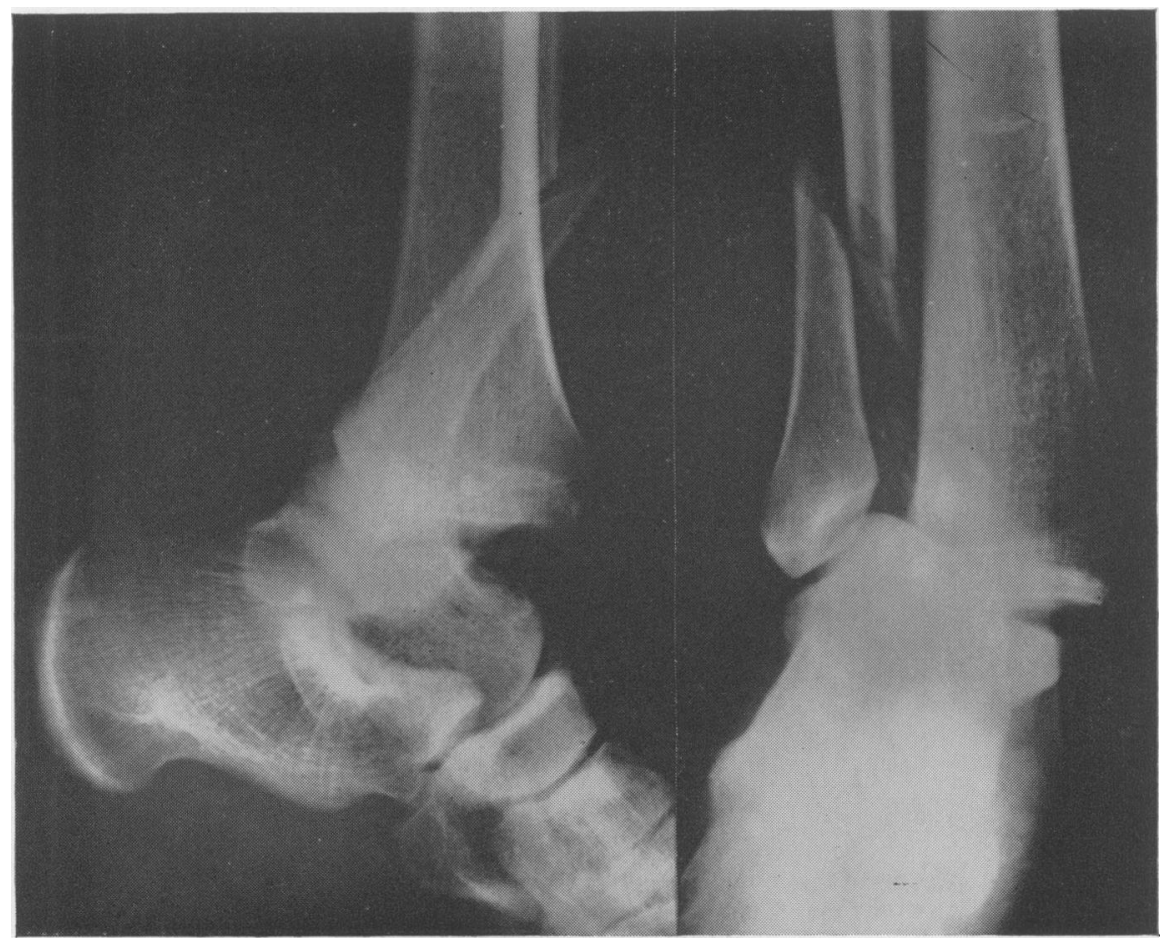

FIG. 9. This abduction fracture may be grouped in the Lauge-Hansen pronationeversion (lateral rotation) group, but the obliquity of the fibular fracture is not typical of a lateral rotation injury. Again the normal relationship of the fibula to the tibia at the inferior tibio-fibular joint is lost because of disruption of the syndesmosis (classical diastasis). The horizontal fracture of the medial malleolus is noted.

consequent disruption of this joint and complete separation of the tibia from the fibula (i.e. classical diastasis). This has serious functional implications. It must, however, be said that in this fracture complex there can be included a fracture of the posterior tibial margin, but this may be of little practical significance. On the other hand, in our classification the anatomical nature of the abduction fracture is stressed by division into uni-, bi- and 'tri-malleolar' types, but like Ashurst, a consideration of the possibility of complete disruption of the inferior tibio-fibular joint leads us to retain the subdivision of this group according to the level of the fibular fracture-an anatomical feature of considerable funtional importance. Lauge-Hansen pays direct attention to rupture of the medial ligament rather than fracture of the medial malleolus as the earliest stage of this mechanism of injury. Two characteristic abduction fractures are illustrated (Figs. 8 and 9).

\section{Discussion}

It must be repeated that any classification of ankle fractures should provide information regarding the nature of the fracture and its associated ligamentous damage, so permitting a logical plan of management. A classification falling short of this ideal can be supplemented by information obtained from radiographs of the ankle, strained under anaesthesia. This will often demonstrate significant ligamentous rupture and confirm the mechanism of production of the total ankle injury.

Our classification, if only founded on an anatomical basis, would over-simplify the ankle injury, and this is particularly true of the lateral rotation, lateral malleolus group. However, there is the second, more important, consideration of the direction of the force producing the injury, i.e. abduction, adduction, etc., which by the anatomical details noted at $\mathrm{X}$-ray give the indication for supplementary strain views under anaesthesia. This classification immediately brings to the surgeon's notice the possible ligamentous injuries that co-exist with radiologically visible fractures whose characteristics point to the direction of the force producing them. Indeed, this 
classification would allow us to answer in the affirmative the questions already posed, i.e.:

(a) That patterns of fracture seen on X-ray can be related directly to the force producing them ;

(b) That certain fractures are associated with important ligamentous injuries, whose existence can be implied from the radiological picture (although strain views under anaesthesis may well be necessary); and

(c) When these ligamentous ruptures are recognized or when fractures co-exist both on medial and lateral sides of the ankle, instability can be said to be present.

Lauge-Hansen's and Ashurst's classifications can equally provide answers to the questions posed. That this is so is due to the fact that there is very little difference between them. If one admits that the pronation-abduction and pronation-eversion (lateral rotation) subdivisions are simply variations on an abduction theme and if one drops the somewhat unnecessary word referring to the position of the foot at the time of injury, viz. pronation or supination, then these two classifications are very similar indeed.

Both classifications, but particularly that of Ashurst \& Bromer (1922), by attempting to imply an ordered progression of events consequent upon injury add to the complexity of the method without necessarily adding to its comprehension. This is the danger and, perhaps, the fallacy of equating directly experimental evidence to clinical problems. It would, however, be foolish to belittle the classifications of Lauge-Hansen and Ashurst \& Bromer, but it would seem wise to adhere to the simpler, more readily understood system outlined in Table 3 . Indeed this simplified, though admittedly not original, classification is given in a more detailed and explicit form in the 'Appendix' to this paper (pp. 210-211).

\section{Acknowledgments}

Our thanks are due to Mr D. Ll. Griffiths and Professor R. Roaf for their encouragement and help in the compilation of this paper. We record our gratitude to Mrs V. Thornton and Mrs M. Bevens for their secretarial help. The illustrations have been produced for us by $\mathrm{Dr} R$. Ollerenshaw, Department of Medical Illustration, Manchester Royal Infirmary.

\section{References}

Ashurst, A.P.C. \& Bromer, R.S. (1922) Classification and mechanism of fractures of the leg bones involving the ankle joint. Arch. Surg. 4, 51.

BonNeT, D. (1845) Traité de Maladies des Articulations, Vol. 2, p. 428. Lyon.

COOPER, Astley (1822) A Treatise on Dislocations and Fractures of the Joints. London.

Cunningham, D. (1964) Textbook of Anatomy, 10th edn. (Ed. by G. Romanes). Oxford University Press.

Destor, E. (1911) Traumatismes du Pieds et Rayons-X. Masson, Paris.

HoNigSCHMIED, J. (1877) Leichenexperimente über die Zerriesungen der Bände der Sprunggelenk mit Rucksicht auf die Entstehung der Indireckten Knockelfractures. Disch. Z. Chir. 8, 329.

Lauge-Hansen, N. (1948) Fractures of the ankle. Arch. Surg. 56, 259.

Lauge-Hansen, N. (1950) Fractures of the ankle. II. Combined experimental-surgical and experimental-roentgenological investigations. Arch. Surg. 60, 957.

LAUGE-HANSEN, N. (1952) Fractures of the ankle. IV. Clinical use of genetic-roentgen diagnosis and geneticreduction. Arch. Surg. 64, 488.

Lauge-Hansen, N. (1953) Fractures of the ankle. V. Pronation dorsiflexion fractures. Arch. Surg. 67, 813.

Maisonneuve, M.J.G. (1840) Recherches sur la Fracture du Péroné. Arch. gen. Med. 1, 165, 433.

MoNK, C.J.E. (1966) The mechanism of ankle fractures. M.Ch.(Orth.) thesis, Liverpool.

Quenu, E. (1912a) Étude critique sur les fractures du coude-pied. I. Rev. Chir. (Paris), 45, 211.

QUENU, E. (1912b) Étude critique sur les fractures du coude-pied. II. Rev. Chir. (Paris), 45, 416.

Quenu, E. \& Mathieu, P. (1912) Étude critique sur les fractures du cou-de-pied. III. Rev. Chir. (Paris), 45, 560.

Rochet (1890) Du mécanisme des luxations doubles de l'Astragale. Rev. Orthop. 1, 269, 401.

Rose, G.K. (1962) Modern Trends in Orthopaedics 3-Fracture Treatment (Ed. by J. M. P. Clark), chap. 8. Butterworths, London.

Tanton, J. (1916) Fractures du membre inferior. Nouveau Traité de Chirurgie. Bailliére, Paris.

Tillaux, P.J. (reported by Gosselin) (1872) Rapports Bulletins de l'Academie de Médicin, Paris, Series 2, 1, 817. 
R. S. Phillips, C. J. E. Monk and G. A. Balmer

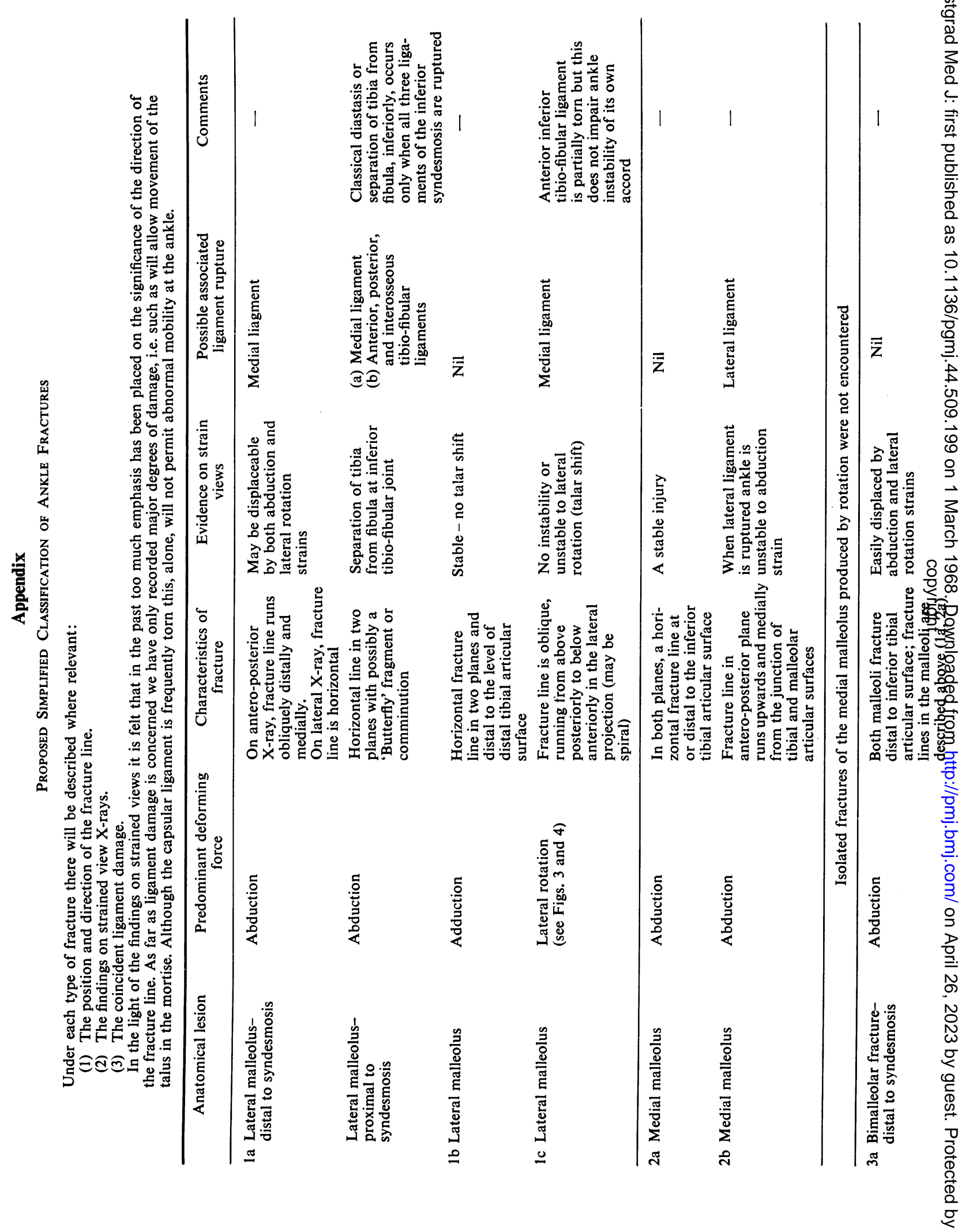


象

茲

要

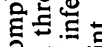

ชั

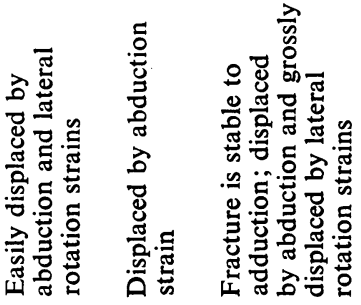

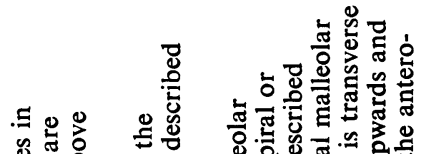

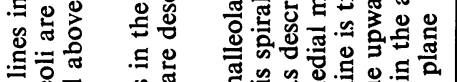

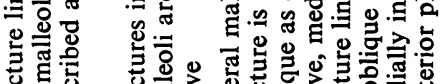

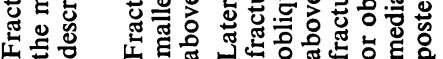

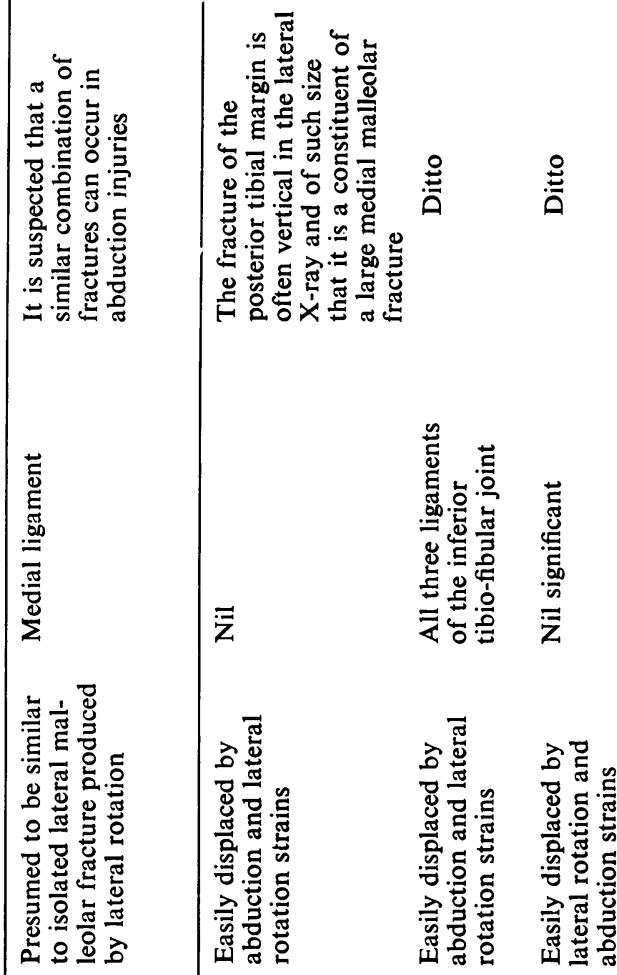

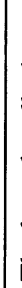

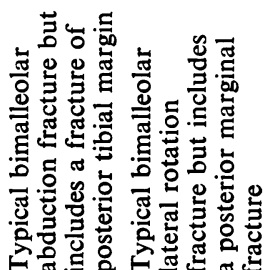

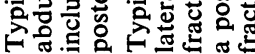

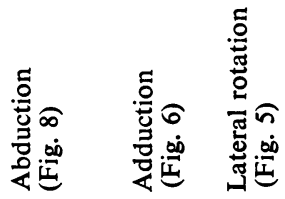

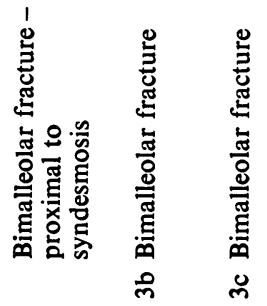

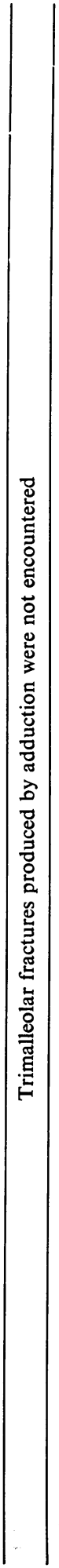

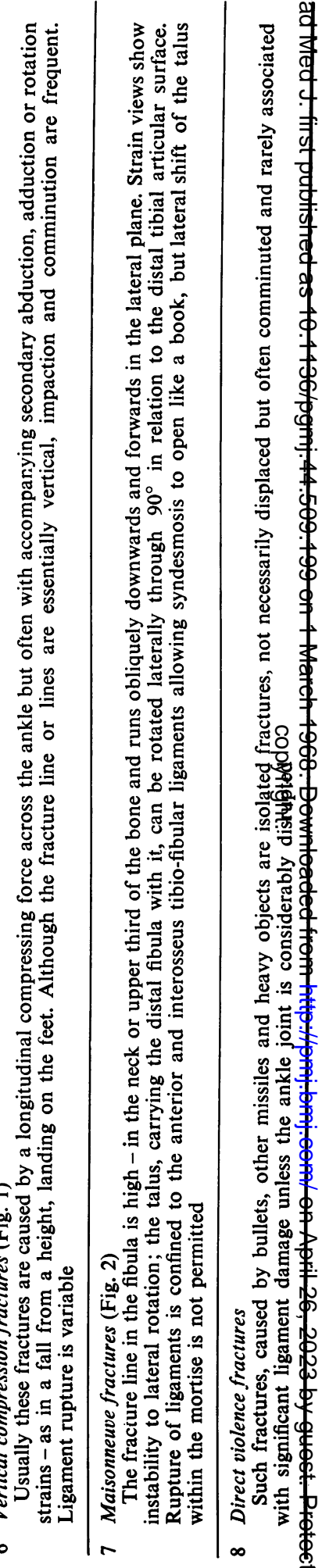

